\title{
Memórias subterrâneas, histórias (re)visitadas: a contribuição da metodologia da história oral em estudos de grupos étnicos
}

\author{
Claudete de Sousa Nogueira*
}

\section{Introdução}

\begin{abstract}
A memória, onde cresce a história, que por sua vez a alimenta, procura salvar o passado para servir o presente e 0 futuro. Devemos trabalhar de forma que a memória coletiva sirva para a libertação e não para a servidão dos homens.

Jacques Le Goff (1996, p. 477).
\end{abstract}

Este artigo tem por objetivo refletir sobre a contribuição da história oral em estudos envolvendo memória e identidade de grupos étnicos. As questões aqui problematizadas fazem parte dos resultados de duas pesquisas, recentemente concluídas, que consistiram em reconstruir a memória de afro-brasileiros a partir da metodologia da história oral. Essas pesquisas tiveram como finalidade transpor para a linguagem escrita uma memória transmitida pela oralidade e restrita aos círculos familiares.

* Doutora em Educação pela Universidade Estadual de Campinas (UNICAMP), mestre em história pela Universidade Estadual Paulista (UNESP). Atualmente é professora assistente do Departamento de Didática da UNESP/Araraquara. 
A primeira pesquisa ${ }^{1}$ teve como objetivo investigar o processo de identificação e transmissão de saberes a partir de uma prática cultural negra do interior paulista denominada batuque de umbigada, e a segunda, ${ }^{2}$ reconstituir as histórias de vida e cultura de afro-brasileiros na cidade de Itu, interior de São Paulo.

A partir da coleta de depoimentos dos batuqueiros e batuqueiras de Piracicaba, Capivari e Tietê e dos moradores mais antigos da cidade de Itu, foi possível conhecer aspectos da vida e da cultura desses grupos afro-brasileiros e de seus ancestrais.

Os depoimentos orais foram articulados a partir do conceito de identificação, aqui compreendido como um processo em que identidades tornam-se plurais, como defende Hall (2003), não fixas, mas suspensas, em transição, entre diferentes posições. São essas identidades que retiram seus recursos de diferentes tradições culturais ao mesmo tempo e que são o produto desses complicados cruzamentos e misturas culturais, cada vez mais comuns num mundo globalizado.

No interior do estado de São Paulo, as manifestações afro-brasileiras, de uma forma geral, misturaram-se com a cultura caipira, marcando-se pela reelaboração de símbolos, sincretismos e mestiçagens. O modo de vida caipira é caracterizado por uma sociabilidade fundada nas relações familiares, na vizinhança e em unidades sociais, como os arraiais, bairros ou vilas (Setubal, 2006; Nepomuceno, 1999). Assim, a relação entre as manifestações culturais negras e essa vivência caipira possibilita entendê-las como parte de um mesmo complexo. Além disso, é possível ampliar esse campo de análise quando se consideram as relações de dominação com padrões personalistas, a vida religiosa marcada por ritos do catolicismo, por festas e comemorações dos santos de sua devoção, e uma forte tradição oral. Essas características estão expressas nas modas de viola, nos sambas e batuques rurais, nos cateretês, cururus, cocos etc. (Wissembach, 1998).

1 Tese de doutorado intitulada Batuque de umbigada paulista: memória familiar e educação não formal no âmbito da cultura afro-brasileira, defendida em 2009, na UNICAMP, sob orientação da Prof. ${ }^{a}$ Dr. ${ }^{a}$ Olga Rodrigues de Moraes Von Simson.

2 A pesquisa fez parte do Programa de Preservação do Patrimônio Histórico urbano do programa Monumenta sob a coordenação da Demacamp. Participaram do projeto como pesquisadores: Amauri Tadeu Barbosa Nogueira, Claudete de Sousa Nogueira e Sylvio F. Batalha Silveira. Também se envolveram na pesquisa os membros da UNEI (União Negra Ituana). 
Nessa perspectiva, a opção pela metodologia da história oral possibilitou reconstruir, a partir da memória dos depoentes, aspectos de sua cultura e experiências cotidianas, até então esquecidas ou pouco estudadas. Esse processo de rememoração trouxe à tona elementos que contribuíram para a (re)construção de memórias, assim como de identidades enquanto sujeitos étnicos. Ou seja, o contato com os pesquisadores proporcionou um espaço de reflexões por meio das conversas, depoimentos, relatos de experiências conjuntas, resultando no reconhecimento da necessidade de dar visibilidade à sua cultura e na ampliação do diálogo com o poder público local.

No decorrer da pesquisa, a cultura afro-brasileira foi concebida como uma teia, em que significados e interpretações foram construídos pelo grupo que vivenciou o batuque de umbigada, cujos membros tornam-se intérpretes e transmissores, a partir do momento em que herdam essa cultura e recebem ensinamentos de seus ancestrais. Partimos do pressuposto de que essa vivência cultural expressa a existência de uma tradição oral afro-brasileira como ponto fundamental para a reconstituição de uma história local. Nesse contexto, foram considerados os mitos e a visão de mundo que fazem parte das experiências e vivências do grupo.

Para tanto, optou-se pela análise qualitativa, com observação participante, procedimento realizado com o objetivo de conhecer o grupo e de compreender seu universo cultural. $\mathrm{O}$ acompanhamento de alguns momentos da vida cotidiana, assim como a participação nos eventos e apresentaçóes feitas pelo grupo de batuqueiros e batuqueiras, contribuiu para se compreenderem as relações internas e externas estabelecidas entre eles e a sociedade mais ampla.

Ao realizarmos a coleta de depoimentos orais visando à constituição de uma história de vida, concordamos com Queiroz (1988), que a define como "relato de um narrador sobre sua existência através do tempo, tentando reconstruir os conhecimentos que vivenciou e transmitir a experiência que adquiriu" (Queiroz, 1988, p. 20).

As fontes imagéticas também desempenharam papel fundamental, porque contribuíram para a compreensão do passado, possibilitando o acompanhamento das transformações que envolvem essa cultura. Os registros fotográficos coletados durante a pesquisa de campo serviram como suporte detonador da memória dos depoentes, além de serem fontes complementares dos dados obtidos. 


\section{O universo das pesquisas: \\ o batuque de umbigada e suas raízes}

O batuque de umbigada, também conhecido como tambu ou caiumba, é uma manifestação cultural trazida para o Brasil pelos escravos de origem bantu que se mantém até os dias atuais nas cidades do interior paulista (Andrade, 1937; Britto, 1986; Simson; Gusmão, 1989; Nogueira, 2009).

O batuque de umbigada conseguiu se manter através do tempo, passando de geração para geração. Faz-se com instrumentos como o tambu, uma espécie de tambor feito de tronco oco de árvore; o quinzengue, um tambor mais agudo que faz a marcação rítmica do tambu e nele se apoia; as matracas, que são os paus que batem no tambu do lado oposto do couro; os guaiás, ou chocalhos de metal em forma de cones ligados. Nessa característica dança, homens e mulheres formam duas fileiras que se defrontam, encontram-se no centro do salão, fazendo passos variados que terminam com a umbigada.

Atualmente, as cidades de Tietê, Capivari e Piracicaba continuam sendo espaços onde essa manifestação se encontra presente. O Treze de Maio em Piracicaba, o Sábado de Aleluia em Capivari e a Festa de São Benedito em Tietê são algumas das ocasiões em que passado e presente se confundem na dança de umbigada, nos reaquecimentos dos tambores ao calor da fogueira, nos longos versos improvisados em que homens e mulheres, jovens e velhos (re)vivem um ritual que o tempo não conseguiu apagar.

Originário das áreas rurais, o batuque de umbigada também já foi chamado samba de roda, samba de bumbo, por vezes samba lenço ou ainda samba rural. A hipótese mais aceita pelos estudiosos sobre sua origem é a de que, com o fim da escravidão e as dificuldades de encontrar trabalho na zona rural, muitas famílias negras migraram para as periferias das cidades levando consigo a memória das manifestações culturais afro-brasileiras - como as danças de umbigada -, que se transformaram com o tempo, ocupando outros espaços na busca de sua continuidade (Andrade, 1937; Simson, 2007).

Motivados pelas lembranças e preocupados em transmitir às crianças não só a prática do batuque, mas também a importância de sua manutenção e continuidade, um grupo representado pelos novos integrantes do batuque, juntamente com alguns dos velhos batuqueiros, criou em 2001 uma associação com o objetivo de transmitir conscientemente os ensinamentos do batuque, das danças afro-brasileiras e da ancestralidade de sua cultura. Além do 
trabalho com as crianças, atualmente o grupo desenvolve oficinas abertas de batuque e apresentações públicas.

A pesquisa que desenvolvi no doutorado teve como objetivo compreender o processo de identificação e transmissão de saberes a partir dessa prática cultural negra.

Para tanto, por meio da coleta de depoimentos orais com os velhos e novos batuqueiros e batuqueiras e entrevistas coletivas com grupos familiares, ${ }^{3}$ busquei despertar o que a memória guarda sobre as experiências vividas e compartilhadas. Foram privilegiados os depoimentos dos velhos batuqueiros (com mais de 70 anos), bem como dos antigos moradores dos bairros com grande concentração de famílias negras das cidades de Tietê, Piracicaba e Capivari. Além disso, ouvi o depoimento de vários batuqueiros e batuqueiras que representam a nova geração, isto é, aqueles que se envolveram com o tambu recentemente. Os depoimentos coletados foram fundamentais por representarem o elo vivo entre o passado e o presente. ${ }^{4}$ Pude observar, nesses depoimentos, a importância da manutenção e transformação dessa prática cultural na vida dos membros do grupo e no convívio em diferentes espaços sociais, seja na comunidade ou fora dela.

\section{Um estudo sobre os afro-brasileiros na cidade de Itu}

A cidade de Itu, que tem a sua história relacionada ao processo de colonização, destacou-se pela economia, ligada primeiramente ao ciclo do açúcar, sucedido pelo do café. Essa trajetória histórica se reflete em suas características arquitetônicas, e é especificamente representada pelo seu reconhecido patrimônio material - igrejas, santuários, fazendas, conventos. No entanto,

3 Para desenvolvimento da pesquisa, considerei a diversidade existente no grupo utilizando como critério a faixa etária e a relação com o tambu. Para tanto, ficou assim dividido: 1) os mais velhos, isto é, o batuqueiros mais antigos, que se autodefinem como herdeiros da tradição, aqueles que detêm o conhecimento sobre os toques dos instrumentos, sobre as danças, sobre o tambu - estes, em torno de 80 pessoas com aproximadamente 70 a 80 anos, buscam se adaptar aos novos tempos, mas lembram com saudades o tempo que consideram como o do "verdadeiro" tambu; 2) os novos batuqueiros, pessoas em geral mais jovens, em torno de 50 pessoas na faixa etária entre 30 e 50 anos que conheceram a tradição por intermédio de algum familiar e foram aos poucos se aproximando e se integrando ao grupo; 3 ) as crianças, que fazem parte de uma associação criada com o objetivo de transmitir conscientemente os ensinamentos do batuque, das danças afro-brasileiras e da ancestralidade de sua cultura.

4 Durante o período de 2005 a 2007, foram coletados em torno de 25 depoimentos orais, sendo que 15 foram transcritos integralmente. $\mathrm{O}$ material está disponível no acervo particular da pesquisadora. 
percebia-se que a identidade histórica da cidade estava exclusivamente relacionada à construção de uma imagem de vertente europeia e/ou das elites dirigentes. Os bens culturais e históricos relacionados aos afro-brasileiros, especificamente ligados ao patrimônio imaterial, não faziam parte da construção da identidade oficial da cidade, permanecendo até então restritos aos círculos familiares, transmitidos de geração para geração. ${ }^{5}$

A pesquisa consistiu em um trabalho de levantamento das diversas manifestações culturais dos negros em Itu e região, ${ }^{6}$ incluindo desde produtos da culinária afro-brasileira, passando pelos grupos de dança e música, pelos trabalhos de artistas e artesãos, até as crenças e práticas religiosas tradicionais. ${ }^{7}$ Concomitantemente ao desenvolvimento de um amplo inventário desses bens culturais, foram realizadas atividades ${ }^{8}$ que tinham como objetivo refletir com os sujeitos históricos do processo sobre a importância de sua cultura na construção da cidade, além de promover e divulgar esses valores estéticos e culturais que foram resguardados e desenvolvidos pela população afro-brasileira na sua trajetória pelas terras paulistas.

O trabalho envolveu a memória oral da população afro-brasileira da região de Itu e tinha como finalidade contribuir para que o próprio grupo percebesse a importância de sua memória na reconstrução da história, além de fortalecer sua identidade. Entre as circunstâncias que favoreceram a realização do projeto, destaca-se o fato de o patrimônio cultural negro de Itu estar situado dentro de uma região do interior paulista que congrega cidades como Bom Jesus de Pirapora, Tietê, Porto Feliz, Capivari, Piracicaba e outras. Essa região abriga uma importante população afrodescendente que

5 De um total de cerca de 135 mil habitantes, segundo o Censo de 2000, a população afro-brasileira de Itu está estimada em 36\% (IBGE, 2000).

6 Considero aqui como patrimônio imaterial, de acordo com a definição da UNESCO, as práticas, representações, expressões, conhecimentos e técnicas, junto com os instrumentos, objetos, artefatos e lugares culturais que lhes são associados, e que as comunidades, os grupos e, em alguns casos, os indivíduos reconhecem como parte integrante de seu patrimônio cultural.

7 Cerca de 200 pessoas envolveram-se na pesquisa, o que incluiu a coleta de depoimentos orais, organização e realização de uma feira afro-brasileira e reunião de materiais para a organização e publicação de um livro intitulado Memória afro-brasileira em Itu, publicado pela Editora Demacamp (Nogueira; Nogueira; Silveira, 2008).

8 Foram realizados encontros coletivos com os antigos moradores da cidade de Itu para esclarecimentos sobre o objetivo da pesquisa e posteriormente coleta de depoimentos orais; visitas técnicas a ruas e bairros majoritariamente habitados por negros; organização e realização da $1^{\text {a }}$ Feira Afro-Brasileira em Itu; organização e publicação de um livro. 
possui características culturais comuns, dadas pelas circunstâncias históricas específicas da colonização e do sistema escravocrata que ali se desenvolveu (Ianni, 1989; Petrone, 1968; Ricci, 1993; Sousa, 1998).

Essa cultura é rica nas mais variadas áreas: culinária, religião, música, celebrações. Em Tietê, por exemplo, acontece tradicionalmente uma festa a festa de São Benedito - em que, às celebrações oficiais da igreja católica, agrega-se uma variedade incrível de manifestações de dança e música negras, que ainda hoje atrai uma quantidade imensa de turistas provenientes de outras cidades próximas e até da capital. Cidades como Bom Jesus de Pirapora têm sido apontadas por pesquisadores como pontos de convergência do samba rural paulista praticado em toda a região. Esses exemplos mostram que Itu está situada numa região que constituiu, num passado não muito remoto, um sistema rico de trocas simbólicas entre a sua população afro-brasileira (Ianni, 1989; Manzatti, 2005; Nogueira, 2009).

A organização do trabalho envolveu vários pesquisadores das áreas de história, geografia e antropologia, além de integrantes da comunidade negra da cidade e da UNEI (União Negra Ituana). ${ }^{9}$ O trabalho desenvolvido em Itu contribuiu para que houvesse uma maior mobilização e organização por parte de uma importante parcela da população afro-brasileira da cidade em torno da preservação de seu acervo cultural. Também contribuiu para o fortalecimento, em termos materiais e imateriais, da União Negra Ituana como um centro de promoção da cultura afro-brasileira local.

\section{Memórias subterrâneas: histórias compartilhadas}

Segundo Simson (2003), memória é a capacidade humana de reter fatos e experiências do passado e retransmiti-los às novas geraçôes através de diferentes suportes empíricos (voz, música, imagem, texto etc.). Para a

9 Projeto realizado através da parceria entre a Demacamp (empresa de projetos sociais e culturais), a UNEI, entidade de caráter sociocultural, e a RuralTur Turismo, agência especializada em turismo e eventos no meio rural. As atividades culturais e algumas reuniôes foram realizadas na Fazenda Rosário, construída em 1756, no auge do período colonial, e atual referência em turismo rural. O projeto fez parte do Programa de Preservação do Patrimônio Histórico Urbano do programa Monumenta, vinculado ao Ministério da Cultura e com financiamento do BID/UNESCO. Participaram da organização e pesquisa: Amauri Tadeu Barbosa Nogueira (FFLCH/USP), Claudete de Sousa Nogueira (FE/UNICAMP) e Sylvio F. Batalha Silveira (IFCH/UNICAMP). 
pesquisadora, entre a memória individual e a coletiva destacam-se as memórias subterrâneas ou marginais, que correspondem às versões sobre o passado dos grupos dominados de uma dada sociedade.

Essas memórias, que não estão monumentalizadas e nem gravadas em suportes concretos como livros, fotografias, CD-ROMs, obras de arte, são geralmente mantidas no âmago familiar ou em grupos sociais dominados, e cuidadosamente passadas de geração a geração.

Estas memórias se expressam quando conflitos sociais as evocam ou quando os pesquisadores que se utilizam do método biográfico ou da história oral criam as condições para que elas emerjam e possam então ser registradas, analisadas e passem então a fazer parte da memória coletiva de uma dada sociedade. (Simson, 2003, p. 15).

Para minhas pesquisas, essas memórias familiares foram pensadas como construções coletivas, "uma corrente de pensamento contínuo que retém do passado somente o que está vivo ou capaz de viver na consciência do grupo que a mantém" (Halbwachs, 1990, p. 81-82). Na organização e desenvolvimento dos estudos com os afro-brasileiros, pude perceber a existência dessas memórias subterrâneas que foram transmitidas através dos tempos nas histórias, nas músicas, nos gestos relembrados pelos depoentes. Os batuqueiros e batuqueiras, ao rememorarem as histórias passadas do batuque e de sua inserção nessa cultura, aprendendo os passos da dança, as improvisações das letras, a confecção dos instrumentos, demonstram o papel das famílias como "guardiãs" desse conhecimento.

Fortemente enraizados na tradição oral, esses grupos elaboraram ao longo do tempo uma visão de mundo que tem na oralidade a sua referência. Mais do que fontes informativas sobre a história de povos africanos, as tradições orais revelam muito da relação dos seus autores com o conhecimento histórico (Bâ, 1973).

Assim como na África a palavra é memória viva, também podemos perceber que a oralidade tornou-se fundamental no processo de aprendizagem que envolve a cultura negra no Brasil. Na visão de Petronilha Gonçalves e Silva (2003), a tradição oral

[...] é uma manifestação da tradição cultural e, como ela, encerra um conjunto de significados que se apresentam com continuidade e constância 
entre membros de um mesmo grupo étnico-racial. Encontram-se tais significados inscritos em intenções, projetos, posicionamentos, avaliações, articulados no agir e intervir no ambiente. Trata-se de patrimônio ancestral intangível que sobrevive com renovados contornos, como que ocultado, mas sempre compartilhado. (Silva, 2003, p. 185).

Para o desenvolvimento desta pesquisa, parti das considerações de Meihy nas quais destaca que "ainda que a tradição oral também implique entrevista com uma ou mais pessoas vivas, ela remete às questões do passado longínquo que se manifestam pelo que chamamos folclore e pela transmissão geracional, de pais para filhos ou de indivíduos para indivíduos" (Meihy, 1996, p. 45).

São significativas nas falas, assim como nas lembranças compartilhadas pelos depoentes, as menções às experiências familiares e do passado que atuam como referências na vida cotidiana presente, além de serem caracterizadas como fontes de transmissão. Logo nos primeiros encontros com os depoentes, cujo objetivo era explicar os fundamentos dos estudos e seu desenvolvimento, percebeu-se o quanto essas memórias e experiências foram compartilhadas pelos membros do grupo, e como cada detalhe ia aos poucos contribuindo para a reconstituição da história daquela cultura.

No pátio da igreja de São Benedito, ${ }^{10}$ local em que ocorria o samba de terreiro em Itu, foram realizadas algumas das reuniões com o grupo envolvido com o projeto. $\mathrm{O}$ reencontro de alguns dos antigos moradores das ruas das Flores e Santa Cruz, por exemplo, fez com que muitas histórias de amizades, mistérios, conflitos fossem relembradas e contadas. Essas ruas foram habitadas majoritariamente pela população afro-brasileira, que ocupava esse espaço por falta de opção, devido às condições econômicas (Nogueira; Silveira, 2008).

Pude ouvir também, por diversas ocasiões, nas falas emocionadas dos depoentes batuqueiros e batuqueiras, histórias sobre as dificuldades e desafios vivenciados no passado, a participação de membros do grupo no batuque e o processo de iniciação, assim como explicações sobre os rituais e conhecimentos transmitidos de geração para geração. São histórias aprendidas e compartilhadas que contribuem para dar continuidade à tradição, à cultura e às perspectivas do grupo.

10 Esse espaço é bastante significativo para a população afro-brasileira local, pois, após a abolição, tornou-se lugar de encontro para as danças festivas pela liberdade e em homenagem a São Benedito. 
De acordo com as reflexões de Simson, fazem parte da construção compartilhada da memória as "ocasiões em que os membros do grupo se auxiliam mutuamente na tarefa de relembrar, cada um contribuindo com detalhes que detonam processos rememorativos dos outros participantes" (Simson, 2003 p. 15).

Dona Olinda, batuqueira de Piracicaba, guarda em suas memórias o tempo da infância, em que frequentava o tambu e aprendia com os mais velhos:

Eu nasci na Fazenda Bela Vista e eu comecei dançar o batuque em uma fazenda que se chama Janeiro. Eu tinha quatro pra cinco anos. Então, quanto tocava o tambu lá, eu ia passando os batuqueiros e passava no vão das pernas dos batuqueiros. Mas aí, eu dava a vorta e vinha, batia de novo e tornava passar aí, o tempo todo. E aí assim eu continuei... Então quando batia o tambu lá no terreiro eu pedia todo dia pra meu vô. 'Ué, o que aconteceu que vocês veio?.' 'Nós escutemos o Sete Léguas tocar, o barulho do Sete Léguas, nós viemos...' - e assim foi, e eu dancei muito naqueles tempos... (Amaral, 2006).

Dona Olinda também recorda, com saudades, como se vestiam naqueles tempos:

Não podia dançar de calça comprida, não podia dançar de costas de fora, não podia dançar de blusa sem manga, aquela saia de babado daqui até embaixo, todo ano a gente dançava com aqueles babados, tudo balançava, manga por aqui, assim aquelas mangas... Sandálias, sandália fechada... (Amaral, 2006).

No batuque de umbigada, os mestres, ou seja, os mais velhos, dispóem de autoridade perante o grupo, têm o papel de transmitir os saberes dos antepassados por meio da oralidade e da dança. A figura dos mestres ganha uma função fundamental no processo de manutenção da identidade grupal, pois eles representam o elo vivo entre geraçôes e, como mediadores, transmitem a história de um passado vivido e experimentado. Essas histórias se fazem presentes ao rememorarem-se as modas, os desafios, a forma de afinar, de tocar o instrumento, a maneira de lidar com o corpo por meio da dança, enfim, a maneira com que o grupo compreende sua herança cultural. $\mathrm{O}$ batuqueiro Júnior, de Piracicaba, assim relata a influência desses grandes mestres: 
Então, existiam escolas desses grandes mestres, por exemplo, a escola da família Caxias, a escola da família Toledo; eram escolas, e como era uma tradição que se aprende de boca de mestre com ouvido de aprendiz, como diz o mestre Lumumbo, aí, você pegava a influência muito daquele que te ensinava do jeito dele tocar, então as dobras, os improvisos, o jeito de cantar, a forma de construir o verso. Então, se pegava muito essa influência [...] tinha muito das características... (Paula Jr., 2005).

As histórias sobre a escravidão também estão presentes em vários dos relatos, o que permite perceber o quanto alguns depoentes se tornaram depositários da memória do grupo, transmitindo fatos narrados pelos seus ancestrais. É o caso de dona Durvalina de Almeida Campos, nascida na cidade de Itu, que guarda na lembrança as histórias contadas por seu avô:

As histórias que eu ouvia eram as histórias de meu avô. Quando eu tinha uns nove ou dez anos, ele gostava de contar histórias para a gente, e eu gostava de ouvir. Inclusive ele contava história sobre escravidão... Pelo que entendi das histórias dele, ele nasceu na Lei do Ventre Livre... Quando ele nasceu, já não era mais escravo, não trabalhava assim, como escravo. Mas, como sua mãe ainda era escrava, ele trabalhava na fazenda mesma coisa, ajudando a cuidar das crianças dos senhores. (Campos, 2008).

Dona Formosa, também nascida em Itu, relembra emocionada a luta de seus avós pela liberdade:

Meu avô veio do Nordeste, trabalhou na lavoura e foi comprado por três mil e quinhentos réis, lá no Nordeste. O nome dele era Manoel Pacheco... Eles pegaram um nome lá e colocaram nele... Ele queria fugir, mas sempre tinha um vigia olhando. Daí, ele deu um golpe de foice no capataz e o matou... O castigo dele foi andar com um ferro em um dos pés... (Amaral, 2008).

As memórias sobre o período da escravidão, além de revelarem que os escravizados não foram apáticos ou anônimos diante da dominação e que souberam utilizar sua bagagem cultural para viver em uma nova sociedade, proporcionam também que seus descendentes reflitam, com o olhar do presente, sobre os problemas e conflitos vivenciados no cotidiano. Isso 
fica bastante evidente quando relatam suas trajetórias de vida, momento em que esses grupos familiares reconstroem também os conflitos e embates que caracterizaram o período pós-abolição, marcados principalmente pela luta em prol da sobrevivência. Nos depoimentos de membros das famílias, estão presentes as mágoas, as revoltas e as indignações decorrentes dessa marginalidade. Dona Anicide Toledo, batuqueira de Capivari que trabalhou como gari durante muito tempo, desabafa:

Olha, falar bem a verdade, nós trabalhemo aí... Tudo por Deus, pra gente ir até o fim lá, pra gente poder aposentar. Porque o fiscar, pra mim, era racista. Ele aproveitava nas nossas costas, e os brancos não fazia nada, mas ele queria carcar nóis. Quando era gente de cor, ele queria tirar o coro. (Toledo, 2006).

Algumas vezes, o silêncio ou as expressões faciais mostram-se reveladores das percepções e indignações quanto à situação do cotidiano. Isso se evidencia, por exemplo, nos relatos que denunciam discriminação racial por parte das autoridades locais, sejam políticas ou religiosas: nas proibições quanto à aparição pública do batuque, nos momentos em que eram obrigados a andar em um lado específico das praças públicas, entre outros.

No entanto, fica claro que a situação de racismo não passou despercebida pelas pessoas, constantemente vítimas da discriminação. Essa percepção fazia-se notar também nas letras das músicas que, dentro do universo do batuque, retratavam a situação pela qual passavam as famílias. As indignações estavam presentes, como na letra criada por Dona Anicide Toledo, de Capivari, para denunciar a situação do filho que sofria discriminação no trabalho:

Eu moro em Capivari, gosto muito da minha terra, eu moro em Capivari, gosto muito da minha terra, São João que me perdoe, do que eu vou falar aqui.

Precisa acabar o racismo, mas dentro de Capivari.

(Toledo, 2006).

Nascida em Capivari, Dona Anicide trabalhou como gari até se aposentar. Relata em seu depoimento que levou o filho para trabalhar consigo e presenciava com muita tristeza e indignação as humilhações sofridas por ele. Sendo ela uma das poucas mulheres a compor e cantar os pontos do 
batuque, ${ }^{11}$ percebeu então que a denúncia seria possível a partir das letras das músicas, como a transcrita acima.

Por meio dos relatos das experiências vividas, fui percebendo os gestos e expressividades que refletiam as alegrias e as tristezas advindas das vitórias e derrotas por que passavam. Essas lembranças, como afirma Ecléa Bosi (2004), podem aparecer como um tônico ou uma letargia. Neste caso, do vínculo com o passado se extrai a força para a formação da identidade.

Portelli (1997), em suas reflexões sobre a utilidade da memória, alerta para o fato de que não se trata apenas de um depósito passivo, mas também de um processo ativo de criação de significações.

[...] a utilidade específica das fontes orais para o historiador repousa não tanto em suas habilidades de preservar o passado quanto nas muitas mudanças forjadas pela memória. Estas modificações revelam o esforço dos narradores em buscar sentido no passado e dar forma às suas vidas, e colocar a entrevista e a narração em seu contexto histórico. (Portelli, 1997, p. 33).

Ao concluir a pesquisa e analisar seus resultados, ficou nítido o sentido da ligação com o legado cultural que, mesmo ressignificado e transformado no decorrer do tempo, serve ainda de referência para os afro-brasileiros. Ao reconstruírem suas histórias de vida, acabam reconstruindo também a história do grupo familiar, misturando, muitas vezes, lembranças suas e de seu grupo. Essa reconstrução é fundamental para que se estabeleça a identidade atual na família, destacando-se, nos relatos, o orgulho e a percepção de responsabilidade pelo fato de serem "herdeiros" dos bens e da tradição deixada pelos antepassados.

\section{Considerações finais}

Segundo Portelli, a verdadeira contribuição que os pesquisadores da história oral podem oferecer à comunidade consiste em "fazer com que sua

11 Na tradição do batuque de umbigada, cabe aos homens a criação dos pontos, assim como tocar os instrumentos. As mulheres seriam responsáveis pela coreografia, pela dança. No desenvolvimento da pesquisa, encontramos duas exceções: o caso de Dona Anicide, a única mulher que compõe e canta, e Dona Maria, a única mulher que toca o tambu. 
voz seja ouvida, levá-la para fora, em pôr fim à sua sensação de isolamento e impotência, em conseguir que o seu discurso chegue a outras pessoas e comunidades" (Portelli, 1997, p. 31).

Contudo, mais do que "dar voz", a história oral permite que os grupos envolvidos reinterpretem suas memórias e as incorporem a uma luta social. $\mathrm{O}$ ato de relembrar ou de compartilhar a memória proporciona sólidas pontes de relacionamento entre os indivíduos, porque está alicerçado numa bagagem cultural comum e, talvez por isso, conduz à ação (Simson, 2003).

Ao desenvolver as pesquisas, pude perceber o quanto a metodologia da história oral foi fundamental para o registro dessas vozes que permitiram reconstruir histórias de lutas, conflitos, discriminações e resistências vivenciadas no passado e no presente. Esse exercício de reconstituição do passado possibilitou a abertura de um espaço para a reinterpretação dessas memórias subterrâneas, por parte dos sujeitos envolvidos, a partir do processo de compartilhamento.

Ao incorporar sua memória à memória da cidade, os afro-brasileiros de Itu, assim como os batuqueiros e batuqueiras de Piracicaba, Capivari e Tietê, passaram a refletir um pouco mais sobre seu papel enquanto cidadãos em sua região, fortalecendo a identidade e o sentimento de pertencimento. Nesse sentido, o trabalho desenvolvido por meio da história oral contribuiu para que houvesse uma maior mobilização e organização por parte de uma importante parcela da população afro-brasileira da cidade em torno da preservação de seu acervo cultural.

Esses grupos se constituem como sujeitos, aqueles que preservam e transmitem uma memória coletiva, ressignificando valores, símbolos, códigos e representações. Desse modo, consiste em uma importante função social relembrar as memórias esquecidas ou desconhecidas, contrapondo a memória oficial. Além disso, percebe-se o interesse desses sujeitos no sentido de preservar sua história e sua identidade.

Assim sendo, as narrativas dos batuqueiros e batuqueiras de Piracicaba, Capivari e Tietê e dos moradores da cidade de Itu revelaram aspectos de uma prática cultural que atravessou gerações, transformando-se no decorrer dos tempos. Do chão dos terreiros dos batuqueiros às ruas da periferia e dos territórios negros, das festas familiares às apresentações públicas nos palcos, dos lares às associações, foram criados espaços que possibilitaram essas experiências de socialização e de transmissão de valores, nas quais negros e negras se (re)organizaram, construindo identificações que têm por base uma memória coletiva transmitida pela tradição oral. 


\section{Referências}

ANDRADE, Mário. Samba rural paulista. Revista do Arquivo Municipal, ano IV, v. XLI, 1937.

BÂ, Amadou Hampâté. A palavra, memória viva na África. Correio da UNESCO: África e sua História, Rio de Janeiro, ano 1, n. 1, 1973.

BOSI, Ecléa. O tempo vivo da memória: ensaios de psicologia social. São Paulo: Ateliê, 2004.

BRITTO, Iêda Marques. Samba na cidade de São Paulo (1900-1930): um exercício de resistência cultural. São Paulo: FFLCH/USP, 1986.

CARNEIRO, Edison. Folguedos tradicionais. Rio de Janeiro: Funart, 1982.

HALBWACHS, Maurice. A memória coletiva. São Paulo: Vértice, 1990.

HALL, Stuart. A identidade cultural na pós-modernidade. Rio de Janeiro: DPA Ed., 1998.

. Da diáspora: identidades e mediações culturais. Belo Horizonte: UFMG; Brasília: Representações da UNESCO no Brasil, 2003.

IANNI, O. Uma cidade antiga. Campinas: UNICAMP, 1989. (Coleção Tempo e Memória).

INSTITUTO BRASILEIRO DE GEOGRAFIA E ESTATÍSTICA. Censo demográfico 2000. Rio de Janeiro: IBGE, 2000. Disponível em: <http://www.ibge.gov.br/home/ estatistica/populacao/censo2000/>. Acesso em: 10 ago. 2013.

LE GOFF, Jacques. História e memória. Campinas: Ed. UNICAMP, 1996.

MANZATTI, Marcelo Simon. Samba paulista, do centro cafeeiro à periferia do centro: estudo sobre o samba de bumbo ou samba rural paulista. 331 p. Dissertação (Mestrado em Ciências Sociais) - PUC-SP, São Paulo, SP, 2005.

MEIHY, José Carlos Sebe Bom. Manual de história oral. São Paulo: Loyola, 1996.

NEPOMUCENO, Rosa. Música caipira: da roça ao rodeio. São Paulo: Editora 34, 1999.

NOGUEIRA, Claudete de Sousa. Batuque de umbigada paulista: memória familiar e educação não-formal no âmbito da cultura afro-brasileira. 160 p. Tese (Doutorado em Educação) - UNICAMP, Campinas, SP, 2009.

NOGUEIRA, Claudete de Sousa; NOGUEIRA, Amauri Tadeu Barbosa; SILVEIRA, Silvio F. Batalha. Memória afro-brasileira em Itu/SP. Campinas: Demacamp, 2008.

PETRONE, Maria Thereza Schorer. A lavoura canavieira em São Paulo: expansão e declínio (1765-1851). São Paulo: Difel, 1968. 
PORTELLI, Alessandro. O que faz a história oral diferente. Projeto História: Revista do Programa de Estudos Pós-Graduados de História, São Paulo, v. 14, p. 25-39, fev. 1997.

QUEIROZ, Maria Isaura Pereira de. Relatos orais: do "indizível" ao "dizível". In: SIMSON, Olga de Moraes Von (Org.). Experimentos com história de vida. São Paulo: Vértice; Revista dos Tribunais, 1988.

RICCI, Magda Maria de Oliveira. Nas fronteiras da independência: os significados da liberdade na região de Itu (1732-1822). 308 p. Dissertação (Mestrado em História) UNICAMP, Campinas, SP, 1993.

SETUBAL, Maria Alice (Org.). Vivências caipiras: pluralidade cultural e diferentes temporalidades na terra paulista. São Paulo: Imprensa Oficial, 2006.

SILVA, Petronilha Beatriz Gonçalves e. Aprender a conduzir a própria vida: dimensões do educar-se entre afrodescendentes e africanos. In: BARBOSA, Lúcia M. de A.; SILVA, Petronilha B. G.; SILVÉRIO, Valter R. (Org.). De preto a afro-descendente: trajetos de pesquisa sobre relações étnico-raciais no Brasil. São Carlos: EdUFSCar, 2003.

SIMSON, Olga R. de Moraes Von. Carnaval em branco e negro: carnaval popular paulistano (1914-1988). Campinas: Ed. da Unicamp; EDUSP; Imprensa Oficial, 2007.

. Memória, cultura e poder na sociedade do esquecimento. Revista Acadêmica, São Paulo, n. 6, p. 14-18, mai. 2003. ISSN 2316-3852. Disponível em: <http://www.fics.edu. br/index.php/augusto_guzzo/article/view/57>. Acesso em: 25 nov. 2013.

SIMSON, Olga R. de Moraes Von; GUSMÃO, Neusa Maria M. de. A criação cultural na diáspora e o exercício da resistência inteligente. Ciências Sociais Hoje, São Paulo, 1989.

SOUSA, Claudete de. Formas de ações e resistências dos escravos na região de Itu: século XIX (1850-1888). 111 p. Dissertação (Mestrado em História) - UNESP, Franca, SP, 1998.

WISSENBACH, Maria Cristina Cortez. Sonhos africanos, vivências ladinas: escravos e forros em São Paulo. São Paulo: Editora Hucitec; História Social/USP, 1998.

\section{Fontes orais}

AMARAL, Olinda de. Batuque de Umbigada. Depoimento concedido a Claudete de Sousa Nogueira, Piracicaba, 28 jan. 2006.

PAULA JR., Antonio Filogênio. Batuque de Umbigada. Depoimento concedido a Claudete de Sousa Nogueira, Piracicaba, 2 fev. 2005.

CAMPOS, Durvalina de Almeida. Memórias da escravidão em Itu. Depoimento concedido a Claudete de Sousa Nogueira, Itu, 8 jul. 2008. 
AMARAL, Formosa Albertina Pacheco. Memória da escravidão em Itu. Depoimento concedido a Claudete de Sousa Nogueira, Itu, 12 jul. 2008.

TOLEDO, Anicide. Batuque de Umbigada. Depoimento concedido a Claudete de Sousa Nogueira, Capivari, 22 jul. 2006.

Resumo: Este artigo tem por objetivo refletir sobre a contribuição da história oral em estudos que envolvem memória e identidade de grupos étnicos. As questôes aqui problematizadas fazem parte dos resultados de duas pesquisas recentemente concluídas, que consistiram em reconstruir a memória de afro-brasileiros com base na metodologia da história oral. Essas pesquisas tiveram como finalidade transpor para a linguagem escrita uma memória transmitida pela oralidade e restrita aos círculos familiares: a primeira investigou o processo de identificação e transmissão de saberes por meio de uma prática cultural negra do interior paulista (Piracicaba, Capivari e Tietê) denominada batuque de umbigada; a segunda reconstituiu as histórias de vida e cultura de afro-brasileiros na cidade de Itu, interior de São Paulo.

Palavras-chave: memória, oralidade, cultura afro-brasileira.

Underground memories, revisited stories: a contribution of the oral history methodology in the studies of ethnic groups

Abstract: This article aims to reflect on the contribution of oral history in studies involving memory and identity of ethnic groups. Problematic issues here are part of the result of two recently completed researches, which consisted of reconstructing the memory of Afro-Brazilians from the methodology of oral history. These surveys were intended to transpose, into written language, memories transmitted by oral tradition and which was confined to family circles. The first was to investigate the process of identification and transmission of knowledge from a black cultural practice in the countryside of São Paulo (Piracicaba, Capivari, and Tietê), the Batuque of Umbigada, and the second to reconstruct the stories and culture of Afro-Brazilians in the city of Itu, São Paulo.

Keywords: memory, orality, Afro-Brazilian culture.

Recebido em 31/01/2013

Aprovado em 15/04/2013 